\title{
A dream come true: Long-term survivors of esophageal cancer
}

\author{
Gail E. Darling, MD
}

\author{
From the Division of Thoracic Surgery, Department of Surgery, Toronto General Hospital, University Health \\ Network, University of Toronto, Toronto, Ontario, Canada. \\ Disclosures: Author has nothing to disclose with regard to commercial support. \\ Received for publication Nov 10, 2015; accepted for publication Nov 12, 2015; available ahead of print Dec 18, \\ 2015. \\ Address for reprints: Gail E. Darling, MD, Toronto General Hospital, University Health Network, 200 Elizabeth \\ St, 9N-955, Toronto, Ontario, Canada M5G 2C4 (E-mail: gail.darling@uhn.ca). \\ J Thorac Cardiovasc Surg 2016;151:733-4 \\ $0022-5223 / \$ 36.00$ \\ Copyright (C) 2016 by The American Association for Thoracic Surgery \\ http://dx.doi.org/10.1016/j.jtcvs.2015.11.015
}

Esophageal cancer has the third-lowest overall survival ${ }^{1}$ $(18 \%)$ after liver/bile duct cancer $(17 \%)$ and pancreatic cancer $(7 \%)$. At the start of my practice, I was told that the purpose of esophagectomy for cancer was to provide durable palliation of dysphagia, and if the patient was cured, this result was considered a bonus. Ghaly and colleagues ${ }^{2}$ report that $33 \%$ of their esophageal cancer patients with cT2N0M0 or higher, survived $\geq 5$ years after esophagectomy. Furthermore, most of these patients survived 10 years. This message is the first important one of this paper: Some patients $(33 \%)$ with locally advanced esophageal cancer can be cured.

Historically, 5-year survival after esophagectomy for cancer was considered a cure. The use of neoadjuvant therapy has increased the overall survival at 5 years, compared with surgery alone, ${ }^{3}$ but has it simply delayed the time to recurrence?

The authors ${ }^{2}$ recommend that follow-up for esophagectomy patients be continued beyond 5 years. The question is: to what end? Aren't patients who survive 5 years cured? Clearly not all are cured; some develop recurrence after 5 years. Are any patients with recurrence salvaged? This message is the second important one of this paper: Yes, 7 of 18 patients with recurrence survived 5 years after treatment for their recurrence. Patients with recurrence can achieve long-term survival.

The other reason for recommending follow-up beyond 5 years is second cancers. One indicator of our success in treating esophageal cancers is that some of our patients live long enough to develop a second cancer. This paper ${ }^{2}$ reminds us that we should not give up on our patients. What a terrible thing it would be to be cured of one of the deadliest cancers, only to die from one that is more often curable.

The last important message of this paper ${ }^{2}$ relates to the other causes of mortality in the long-term survivors. Pulmonary disease was responsible for more deaths than recurrent esophageal cancer in this group of 5-year survivors. As noted in the discussion, ${ }^{2}$ survivors of esophagectomy often have chronic cough and reflux. ${ }^{4,5}$ We are not

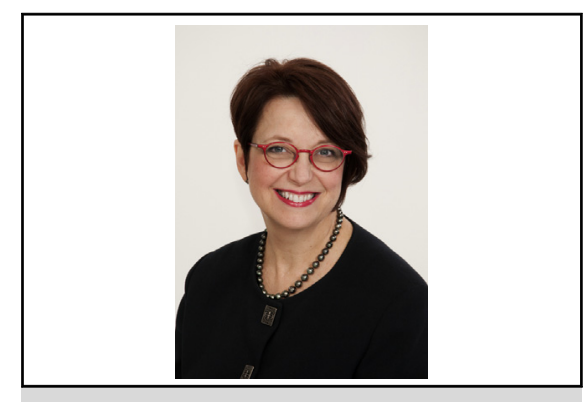

Gail E. Darling, MD

Central Message

Surveillance after esophagectomy is worthwhile, as survivors may be salvaged after the recurrence of cancer, or the development of second cancers.

See Article page 726.

See Editorial page 631

provided with further information on the specifics of the pulmonary disease that caused death, but we know that $25 \%$ of the 5-year survivors had pre-existing pulmonary comorbidities. Did patients die of their pre-existing pulmonary disease, or did chronic reflux and aspiration contribute to their death? Chronic reflux significantly affects patients' quality of life after esophagectomy. Perhaps chronic reflux is more than a quality-of-life issue.

The authors ${ }^{2}$ performed a multivariable analysis to determine which factors are important in the group of patients who achieved 5-year survival. They identified en bloc resection as the most important factor. Although I agree with their practice of performing en bloc resection, and have been an advocate of improving the quality of surgery for esophagectomy, I do not think this study proves this point. As en bloc resection is the favored approach by the authors, we can assume that most of the non5-year survivors were resected by en bloc esophagectomy as well. Further, because en bloc is the preferred approach, one can additionally assume that those resected by transhiatal esophagectomy were likely not fit for an en bloc resection, as reported in the paper. Medical comorbidities may have influenced long-term survival, irrespective of the type of resection. Comparing long-term survivors with non-long-term survivors would be more helpful in determining what factors contribute to long-term survival. This group has previously published the finding that en bloc resection is a significant factor in reducing loco- 
regional recurrence, but most patients die from distant disease. $^{6}$

This paper ${ }^{2}$ provides some much needed good news in esophageal cancer. Some patients are cured and some can be salvaged by aggressive therapy even if they do have recurrence. We are making progress. However, much work remains to be done. Better control of micrometastatic disease is required, but in addition, we need to address the issue of surgical quality. We can record the doses of chemotherapy delivered, we can identify the dose of radiation delivered and the tissues radiated, but how do we measure surgical quality? We count lymph nodes and measure margins. Is this enough? Is en bloc esophagectomy the answer? Variability in surgical practice, and the relative infrequency of esophageal cancer, make the task of addressing this topic in a randomized trial difficult, or likely impossible, but collaboration and aggregate data, collected in the modern era of positron emission tomography-based staging, neoadjuvant therapy, and modern perioperative care, may help direct us to the optimum surgical approach. At that point, the task of delivering high-quality surgery will rest with us.

\section{References}

1. Siegel RL, Miller KD, Jemal A. Cancer Statistics 2015. CA Cancer J Clin. 2015; 65:5-29.

2. Ghaly G, Kamel M, Nasar A, Paul S, Lee PC, Port JL, et al. Locally advanced esophageal cancer: What becomes of 5-year survivors? J Thorac Cardiovasc Surg. 2016;151:726-32.

3. van Hagen P, Hulschof MC, van Lanschot JJ, Steyerberg EW, van Berge Henegouwen MI, Wijnhoven BP, et al. Preoperative chemoradiotherapy for esophageal or junctional cancer. $N$ Eng J Med. 2012;366:2074-84.

4. Greene CL, DeMeester SR, Worrell SG, Oh DS, Hagen JA, DeMeester TR. Alimentary satisfaction, gastrointestinal symptoms, and quality of life 10 or more years after esophagectomy with gastric pull-up. J Thorac Cardiovasc Surg. 2014;147:909-14.

5. Derogar M, Lagergren P. Health-related quality of life among 5-year survivors of esophageal cancer surgery: a prospective population-based study. J Clin Oncol. 2012;30:413-8.

6. Lee PC, Mirza FM, Port JL, Stiles BM, Paul S, Christos P, et al. Predictors of recurrence and disease-free survival in patients with completely resected esophageal carcinoma. J Thorac Cardiovasc Surg. 2011;141:1196-206. 